\title{
Latent Technology as an Outcome of R\&D
}

Department of Economics Working Paper Series

\section{James Cunningham}

Northumbria University, UK

\section{Albert N. Link*}

University of North Carolina at Greensboro

September 2020

Working Paper 20-08

economics.uncg.edu

*Corresponding author 


\title{
Latent Technology as an Outcome of R\&D
}

\author{
James Cunningham \\ Newcastle Business School \\ Northumbria University, UK \\ james.cunningham@northumbria.ac.uk
}

\author{
Albert N. Link* \\ Department of Economics \\ University of North Carolina at Greensboro, USA \\ anlink@uncg.edu
}

* Corresponding author 


\begin{abstract}
This paper focuses on a situation in which a firm decides to sell its non-commercialized technology to another firm rather than commercialize it (a latent entrepreneurial firm), and the other firm then adopts the appearance of an emergent entrepreneur. Using U.S. project data from firms funded through the U.S. Small Business Innovation Research (SBIR) program, we find using a qualitative choice model that firms that do not commercialize their newly developed SBIR-funded technology have a greater probability of selling their technology to another firm than do firms that do commercialize. We also identify other covariates with the probability that such a firm will sell their technology.
\end{abstract}

Keywords: Latent entrepreneurship; Emergent entrepreneurship; SBIR; Commercialization JEL Codes: O32, O33, O38 


\section{Latent Technology as an Outcome of R\&D}

\section{Introduction}

One of the strategies a firm adopts in maintaining and enhancing their competitive position is investing in research and development (R\&D) (Hagedoorn and Wang, 2012). Pursuing such a strategy can lead a firm to setting up a dedicated R\&D department and then developing collaborative relationships with universities, public research organizations, and other firms (Aristei et al., 2016; Kleinknecht and Reijnen, 1992; Veugelers and Cassiman, 2005). These efforts also mean a change in the firm's culture to support and maximize investments in R\&D (Asmawi and Mohan, 2011; Martín-de Castro et al., 2013). A constant challenge and competitive pressure for a firm is thus to ensure that it secures a return on its R\&D investments and that R\&D contributes to overall firm performance (Allen et al., 1980; Fey and Birkinshaw, 2005; Tsai and Wang, 2004).

There are at least five outcomes from a firm's pursuit of R\&D activity: (1) the effort to develop a new or improved technology fails; (2) the R\&D project is successful, and the firm commercializes the technology; (3) the R\&D project is successful, but the firm decides not to commercialize and it holds its non-commercialized technology; (4) the R\&D project is successful, and the firm decides to commercialize the technology through a spin off company; and (5) the R\&D project is successful, and the firm decides not to commercialize it either internally or through a spin off company but the firm sells its technology to another firm.

Caiazza et al. (2020, p. 697) reflect on the strategy trajectory of a latent entrepreneurial firm to becoming an emergent entrepreneurial firm:

A latent form of entrepreneurship exists until no one is able to use knowledge spilling out of its original source to implement entrepreneurial projects and introduce an innovation into the market. However, when an entrepreneur exploits knowledge spillovers to start a new firm, it emerges from its latent form and is known as emergent entrepreneurship. 
In the context of the five scenarios that we outlined above, a firm that has its R\&D project fail or a firm that is successful and commercializes its technology itself (scenarios (1) and (2)) is not relevant to the discussion about latency or emergence. If the firm decides not to commercialize its technology (scenario (3)), it adopts the appearance of a latent entrepreneur; the opportunity exists to commercialize the technology, but the technology remains latent. If the firm decides to commercialize the technology through a spin off entity (scenario (4)), then the latent firm/technology has transitioned into an emergent stage. Finally, if the firm decides to sell the technology that it has not commercialized to another firm, that other firm has adopted the appearance of an emergent entrepreneur (scenario (5)). In this scenario a firm may have invested some organizational resources to initiate commercialization of the technology itself and during this process may decide to sell the technology.

In this paper, we focus on scenario (5), and our focus on scenario (5) is driven entirely by the availability of data as discussed below. Thus, the contribution of this paper is the identification of characteristics of the firms that develop a technology, but rather than commercializing it they decide to sell the technology to another firm. Albeit that this focus is limited in terms of a full understanding of the transition from latent entrepreneurship to emergent entrepreneurship, it does offer, for the first time to the best of our knowledge, an understanding about this particular scenario.

The data that we study in this paper relate to R\&D projects funded through the U.S. Small Business Innovation Research (SBIR) program. Latent entrepreneurship and the SBIR program are described, with reference to the extant literature, in Section 2 below as are the relevant data studied in this paper. In Section 3, we present the statistical results about the probability that a SBIR-funded firm will develop a technology, decide not to commercialize it, and instead sell the technology rights to another firm. We conclude the paper in Section 4 with a discussion of our findings.

\section{Literature Considerations}

\subsection{Latent Entrepreneurship}


The wider and well established body of knowledge with respect to latent entrepreneurship has focused on issues such as determinants (Musuda, 2006), barriers (Fernández-Serrano, and Romero, 2014; Grilo and Thurik, 2006; Fatoki and Chindoga, 2012), gender (Bönte and Piegeler, 2013), and cultural identity (Audretsch et al., 2017). Recent perspectives on latent entrepreneurship relate to the knowledge spillover theory of entrepreneurship (see Caiazza et al., 2020).

The creative construction circle of latent and emergent entrepreneurship, as posited by Caiazza et al. (2020, p. 689), consists of four steps and identifies a "transition between unrealized and latent entrepreneurship, where the entrepreneur identified opportunities but did not market them" in step two. In particular, these authors argue that the latent entrepreneurship transfer manifests itself into new venture creation that can exploit already created knowledge and bring that knowledge into the marketplace - step four. Step three consists of the entrepreneur assembling the necessary resources and relationships in the preparation phase of starting a new venture. In essence, the entrepreneur is the "catalyst for constructive creation," but this does not lead to incumbent firms being destructed. Step three also requires wider entrepreneurial ecosystem support to realize such an outcome (Canter et al., 2020) and this can lead to positive second order societal outcomes (Davidsson and Wiklund, 200; Caiazza et al., 2020).

\subsection{Public Sector Entrepreneurship, the U.S. SBIR Program, and the SBIR Data}

Policy makers have a clear role to play in supporting latent entrepreneurs particularly during stages three and four of the creative construction circles posited by Caiazza et al. (2020). Based on a study of Japanese latent entrepreneurship, Masuda (2006) concludes that policy makers should enact policy instruments that are targeted at supporting latent entrepreneurs. This effort implies creating a conducive environment that enables latent entrepreneurs to exploit transferred knowledge on the supply side for their own ends, such as through the creation of a spin-out firm.

The U.S. Small Business Innovation and Research (SBIR) program is one of the public sector entrepreneurship policy instruments that is used to support knowledge and technology transfer from knowledge creators (latent entrepreneurs) to firms and individuals that want to exploit technology (emergent entrepreneurs). Leyden and Link (2015) and Hayter et al. (2018) refer to 
the SBIR program as an example of public sector entrepreneurship. "What makes the public sector entrepreneurial is that it can be associated with the recognition and exploitation of new opportunities, and thus its actions are characterized by uncertainty" (Hayter et al., 2018, p. 677).

The SBIR program was created through the U.S. Small Business Innovation Development Act of 1982 (Public Law 97-219) in an effort to "support scientific excellence and technological innovation through the investment of Federal research funded ... to build a strong national economy." The SBIR program supports Phase I and Phase II projects. A 6-month Phase I project is a proof of concept project to establish the technical merit and commercial potential of a proposed technology; a 2-year Phase II project is the continuation of a successful Phase I project with the intent of the resulting technology being commercialized. ${ }^{2}$

To be eligible to apply for a Phase I award, generally funded at less than $\$ 150,000$, the for-profit U.S. firm must not employ more than 500 individuals, and a citizen or permanent resident alien of the United States must own more than 50 percent of the business. ${ }^{3}$ About 16 percent of Phase I applications are funded. About 80 percent of firms that received a Phase I award are later invited to apply for a Phase II award, generally not to exceed $\$ 1$ million, ${ }^{4}$ and about one-half of the Phase II applicant firms are funded. ${ }^{5}$

In 2000, the U.S. Congress authorized the National Research Council (NRC), which is part of the National Academies, ${ }^{6}$ to conduct a broad-based study of the SBIR program in anticipation of the program's renewal in 2008. In 2005, the NRC conducted a random sample of Phase II projects,

\footnotetext{
${ }^{1}$ See Link and Scott (2012) and Leyden and Link (2015) for detailed histories of the SBIR program.

${ }^{2}$ For more details about Phase I and Phase II projects, see https://www.sbir.gov (accessed September 15, 2020).

${ }^{3}$ For complete details of the eligibility requirements for application for a SBIR award, also see https://www.sbir.gov (accessed September 15, 2020).

${ }^{4}$ It is not uncommon, especially on DOD awards, for a firm to receive add-ons to its Phase II award thus bringing the total amount of the award to over $\$ 1$ million.

${ }^{5}$ These statistics are averages for the years 1992 through 2010; the underlying data are at https://www.sbit.gov (accessed September 15, 2020).

${ }^{6}$ See https://www.nationalacademies.org/ (accessed September 15, 2020).
} 
funded over the years 1992 through 2001 and awarded by the five largest agencies with SBIR programs (alphabetically): ${ }^{7}$ Department of Defense (DOD), Department of Energy (DOE), National Aeronautics and Space Administration (NASA), National Institutes of Health (NIH), and the National Science Foundation (NSF). The results from the 2005 random survey of Phase II projects funded through these five agencies form the sampling population of Phase II projects studied in this paper. ${ }^{8,9}$ The number of Phase II projects used in this study $(\mathrm{n}=1567)$ are described in Table 1.

Insert Table 1 about here

The variables considered in this paper are defined in Table 2, descriptive statistics on the variables are presented in Table 3, and a correlation matrix of the variables is in Table 4.

Insert Tables 2, 3, and 4 about here

\section{Empirical Analysis}

The focus of the empirical analysis in this paper is to identify statistically covariates with the likelihood that a firm's technology rights to an SBIR-funded Phase II project will be sold to another firm. The dependent variable that approximates this likelihood is emergent. As stated in the Introduction, the focus of this paper is on latent entrepreneurial firms that decided to sell their non-commercialized technology to another firm, and that other firm thus has the appearance of an emergent entrepreneur (scenario (5) above).

\footnotetext{
${ }^{7}$ The largest SBIR program in terms of number of awards and the total dollar amount of awards is at DOD followed by NIH.

${ }^{8}$ A detailed discussion of the NRC's randomization process is discussed in NRC (2008) in Appendix A.

${ }^{9}$ Two additional NRC surveys of Phase II projects were conducted. One was in 2011 for DOD, NASA, and NSF awards; and the other survey was in 2014 for NIH and DOE awards. The data from these subsequent surveys that has been made available to us does not contain information on the amount of the Phase II award, for confidentiality purposes. Since that datum for a Phase II award is central to the analysis in this paper, only information from the 2005 survey is studied in this paper.
} 
The key independent variable held constant in our empirical analysis, so that our analysis mirrors scenario (5), is commercialization. Holding constant the variable commercialization segments our sample of 1567 Phase II projects into latent entrepreneurial firms and non-latent entrepreneurial firms, and thus our analysis allows us to identify characteristics of firms that are related to scenario (5).

As a precursor to our more formal empirical analysis, consider the descriptive statistics in Table 3. 10.5 percent of our sample of 1567 randomly selected Phase II projects have negotiated or sold their technology rights. As shown in Table 5, the mean percent of Phase II projects in firms that sold technology rights to their Phase II project is greater for firms that chose not to commercialize the technology. 13 percent of the firms that sold their technology rights chose not to commercialize their technology, but 10.1 percent of the firms that sold their technology rights also commercialized the technology (either before the sale or in concert with the terms of the sale). ${ }^{10}$ Also shown in Table 5 are the mean values for the other binary independent variables. The means in Table 5 show that firms with previous experience with spinoffs are more likely to sell their new technology and firms without a previous Phase I award in a related technology are more likely to see their Phase II technology. These patterns are complemented by the directional influence of these variables on emergent in Table 6 below.

Insert Table 5 about here

The variables in our model are defined in Table 2, relevant descriptive statistics on all of the variables are in Table 3, and relevant correlation coefficients are in Table 4. Because the dependent variable, emergent, is binary, Probit models were estimated. The average marginal effect from the Probit regression using the complete sample of projects ( $\mathrm{n}=1567)$ is in column (1) in Table 6.

\footnotetext{
${ }^{10}$ We thank an anonymous reviewer for emphasizing that $10.1 \%$ of the firms in the sample that sold their technology rights also commercialized the technology. Perhaps this is a desirable scenario from the perspective of transferring publicly funded technology to society. For those firms for which this is the case, they might not have been successful with their commercialization effort, and thus selling their technology might have been a profitmaximizing strategy. Or, the firms that sold their technology might not have had sufficient internal resources and experitise to research foreign markets; again, the sale of the technology might have been a profit-maximizing strategy.
} 
Insert Table 6 about here

As discussed above, we hold constant in our analysis whether or not the firm commercialized the technology developed from its Phase II SBIR award. For our empirical analysis to correspond to scenario (5), we seek to identify characteristics of the firms that developed a technology but rather than commercializing it decided to sell the technology to another firm. Thus, we expect the sign on the Probit coefficient and on the average marginal effect of commercialization to be negative. Those firms that do not commercialize their own technology are expected to, among possibilities, sell their developed technology to other firms. Referring to column (1) in Table 6, the marginal effect of commercialization is negative, and it is statistically significant at the $0.15-$ level. The probability that the firm will sell its Phase II-developed technology to another firm is 3.1 percentage points greater if the firm did not commercialize its developed technology.

We also hold constant in our analysis the $R \& D$ resources available to the firm through the SBIR program to conduct its Phase II research, and we measure the variable in logarithmic terms to account for nonlinearity, lnaward. And, we hold constant the human capital resources available in the firm to conduct its Phase II research, and we also measure this variable in logarithmic terms, lnemployees.

To the extent that Phase II projects with larger R\&D budgets - which Caiazza et al. (2015) refer to in terms of the production of new knowledge - are more diverse in research scope with greater technology dimensions to sell, the likelihood that the firm will sell the technology is greater. The marginal effect of lnaward is positive, and it is statistically significant at the .15-level. A 1 unit increase in lnaward is associated with an increase of 3.3 percentage points in the probability that the firm will sell its technology.

To the extent that firms have more employees at the time the Phase II award proposal was submitted for possible funding, and thus more human capital to ensure success in commercialization, the likelihood that the firm will sell its technology is less. The average marginal effect of lnemployees is negative and it is statistically significant at the 0.01-level. A 1 
unit increase in lnemployees is associated with a 1.6 percentage point decrease in the probability that the firm will sell its technology.

Regarding the other independent variables in our model, to the extent that firms with founders with business backgrounds are more experienced in the sale of technology than firms without such an experience base, the likelihood that the firm will sell its technology is greater. The average marginal effect of businessbackground is positive and it is statistically significant at the 0.01-level. The probability that the firm will sell its Phase II-developed technology is 5.3 percentage points greater if the firm has a founder with a business background. ${ }^{11}$

To the extent that firms with prior experience in forming spinoff companies are more experienced with dealing with external financial matters and thus more likely to be able to undertake the sale of technology, the likelihood that the firm will sell its technology is greater. The average marginal effect of spinoffs is positive, and it is statistically significant at the 0.01level. The probability that the firm will sell its Phase II-developed technology is 7.3 percentage points greater if the firm has prior experience with establishing spinoff companies.

Finally, we control for whether the firm's current Phase II research is related to a technology that is new to the firm. To the extent that a firm is pursuing a new technology for strategic reasons, the greater the likelihood that it will not seek to sell its developed technology. The average marginal effect of newtechnology is negative, and it is statistically significant at the 0.01-level. The probability that the firm will sell its Phase II-developed technology is 6.1 percentage points less if the technology is new to the firm.

As pointed out in Section 2 above with reference to SBIR awards, a Phase II award is generally less than $\$ 1$ million. And, as pointed out in the note to Table 3, 64 of the 1567 Phase II projects

\footnotetext{
${ }^{11}$ We do not interpret this finding to mean that firms with a larger percent of founders with a business background are more astute when it comes to pursuing the sale of a technology. Rather, this variable simply describes an element of the human capital endowments within the firm. Firms with a larger percent of founders with a business background might apply different decision-making criteria to the tradeoff decision of sell versus commercialization. Unfortunately, there are not sufficient variables in the NRC database to control fully for the characteristics of the Phase II technologies to interpret this finding with reference to homogeneous technologies.
} 
were awarded more than $\$ 1$ million, and most of those awards came from DOD. To the extent that the agency's fixed effect on the model described in column (1) in Table 6 does not fully control for such funding exceptions, and to the extent that funding through add-ons is related to the likelihood that a firm will sell its Phase II technology, we deleted the 64 Phase II projects from the complete sample and re-estimated the Probit model $(n=1503)$. The average marginal effects are in column (2) in Table 6. The sign pattern on the variables is the same as in column (1), and the level of significance on some variables is greater. And, the sign pattern on the variables in Table 6 is identical to the sign pattern on the correlation coefficients in Table 4.

The last column in Table 4 shows the variance inflation factors (VIF) for the independent variables. All of the factors are less than 2.0 suggesting that multicollinearity is not an issue. ${ }^{12}$ Thus, the regression coefficients in Table 6 can be viewed as precise.

\section{Discussion and Concluding Remarks}

Acknowledging the limitations of our study described above in relation to data availability, our focus is on SBIR-funded firms that decide not to commercialize an R\&D project internally or through a spin off company, but to sell its technology to another firm. Our empirical analysis provides new insight into latent entrepreneurship, particularly the creative construction circle of latent and emergent entrepreneurship as posited by Caiazza et al. (2020). As part of an R\&D strategy firms have to decide if they are going to commercialize their own technology or sell that technology to a third party. Natural and legitimate concerns for firms that sell a technology they have created to another firm, are the potential loss of future revenue, jobs, and the competence for exploiting knowledge and technology within the firm (see Becker and Zirpoli, 2017; Grimpe and Kaiser, 2010; Kotabe et al., 2008; Sosa, 2011). We find a marginal effect of commercialization is negative for incumbent firms that have produced new technology but have not commercialized it. Our finding here provides some tentative empirical evidence and furthers the argument posited by Caiazza et al. (2020) that creative construction does not destruct incumbent firms, but provides an opportunity for latent entrepreneurs to acquire knowledge that

\footnotetext{
${ }^{12}$ A rule of thumb is that a VIF score greater than 10 on an independent variable suggests that variable is colinear with another/other independent variables.
} 
assembled with additional resources can address an entrepreneurial opportunity in the market place through emergent entrepreneurship. ${ }^{13}$ Moreover, firms that acquire such technology from another firm become another type of catalyst for constructive creation that those suggested by Caiazza et al. (2020).

Our findings highlight for latent and emergent entrepreneurship to be realized in the case of the SBIR program, the potential technology scope (expansion potential) and forecast increases the probability that the firms will sell the technology to another firm (see Lerner, 1994; Altuntas et al., 2015). In essence, the more attractive the potential technology scope and technological forecast of its utilization across different domains the greater the interest of other firms in acquiring such technology to build their own supply or demand side capacity. Therefore, firms need to consider in the case of latent technologies where is the feasible expansion in technology scope. In adding to the technology scope of a firm, this can add more financial value, broaden the pool of potential acquirers of this latent technology, and achieve a financial return on a successful R\&D project sold on to another firm. This R\&D outcome can contribute to $R \& D$ and firm performance (Falk, 2012; Yeh et al., 2010; Lin et al., 2006) as well as enhancing the skills and competences within the firm.

Our study further adds new empirical evidence to the creative construction circle posited by Caiazza et al. (2020). In stage one of the creative construction circle, Caiazza et al. (2020) suggest that knowledge is not commercialized due to reasons of risk, market uncertainties and individual entrepreneur deficits with respect to skills and abilities. Our study identifies that the business background of founders and their prior experiences with finance associated with spinoff firms and sale of technology are factors that contribute to the firm selling its technology to another firm. This suggests that if firms with deficits of founders with a business background, and their prior financial experiences, the likelihood of knowledge going unrealized (stage one of

\footnotetext{
${ }^{13}$ An alternative interpretation of our finding is based on the scholarship of Tsvetkova and Partridge (2019). They argue, based on the knowledge spillover theory of entrepreneurship (KSTE), that knowledge produced by an incumbent firm that is underused can be a source of knowledge for new business formation. If one thinks of a firm that does not commercialize its own technology as underusing its created knowledge, and if one thinks of the firm that purchases that technology as being involved in a new business formation, then our findings do provide support for the KSTE as applied to emergent entrepreneurial behavior.
} 
the creative construction circle) would increase. This means less of a likelihood of a transition from unrealized to latent entrepreneurship (stage 2) through emergent entrepreneurship in the form of the firm selling its latent technology to another firm. Furthermore, our findings again highlight the importance of human capital in the commercialization of technology (Corolleur et al., 2004). If firms possess such human capital, our study suggests the likelihood that the firm would not sell its technology to another firm.

A consideration that has not been focused on the literature that takes a knowledge spillover perspective of latent entrepreneurship is the strategic purpose of the knowledge created and how this relates to the overall business strategy being pursued by the firm. This is tied to how the firm views and implements its R\&D strategy and whether or not it underpins and is aligned to the firm's business strategy. The 'newness' of the technology may mean that the firm subjects this type of R\&D activity to further organization scrutiny through new product development evaluations (see Carbonell et al., 2004; Hart, 2003; Lukas et al., 2002).

Our study further affirms the essential role of targeted policy interventions that are necessary to contribute to creating conducive environmental conditions for the transition to occur between latent and emergent entrepreneurship. The danger is that knowledge is not fully developed and exploited, and it remains what Caiazza et al. (2020) terms as unrealized entrepreneurship. Therefore, this requires a careful and targeted public sector entrepreneurship program that encourages and makes it economically attractive and legitimate for firms to purse a strategy of selling latent technology to another firm. Moreover, such policy interventions are also needed to support the enhancing of the technology scope to increase the attractiveness and application of latent technologies to a wider range of buyers on market supply or demand side.

There is a need for future studies to extend this study to other public sector entrepreneurship programs that are designed to support transitions between latent and emergent entrepreneurship, particularly the four stages creative construction circle. Another fruitful research avenue is pursuing micro level studies at the individual level to better understand the approaches, behavior, and factors that influence individual actors to sell technology to other firms. In particular, a limitation of our study is the lack of data to control for characteristics of the technologies 
developed thought Phase II SBIR research awards. What would be reasonable is for case studies of SBIR-funded firms to address these characteristics in terms not only of whether the firm commercializes or sells its technology but also in terms of the relationship between technology characteristics and the strategic approach used by firms to make the commercialize or sell decision. The micro level interplay between the strategy of a firm and the decision-making criteria used to commercialize of sell technology as part of their R\&D activities warrant further exploration. Finally, there is a need to measure the societal benefits of latent and emergent entrepreneurship on the economy. Again, we propose that detailed case studies be the relevant vehicle for such analyses. 
Table 1

Data Reduction Process

\begin{tabular}{lcccccc}
\hline & DOD & DOE & NASA & NIH & NFS & All \\
\hline NRC's Survey population & 3055 & 439 & 779 & 1678 & 457 & 6408 \\
Random sample of Phase II projects * & 891 & 154 & 177 & 495 & 161 & 1878 \\
Phase II projects reporting all relevant data & 751 & 137 & 155 & 384 & 140 & 1567 \\
\hline
\end{tabular}

* A discussion of the NRC's random sampling procedure is discussed in NRC (2008). 
Table 2

Definition of Variables

\begin{tabular}{ll}
\hline Variable & Definition \\
\hline emergent & $=1$ if the firm has finalized or is involved in an ongoing negotiation with \\
& another U.S. firm for the sale of the technology rights from its Phase II project: \\
& 0 otherwise \\
& $=1$ if the firm commercialized a technology from its Phase II project: 0 \\
& otherwise \\
commercialization & Natural logarithm of the amount of the Phase II award converted to \$2005 \\
& using the GDP deflator, in 000s \\
lnaward & Natural logarithm of the number of employees in the firm at the time the Phase \\
lnemployees & II project was submitted for possible funding. \\
bussinessbackground & Percent of firm founders with a business background \\
spinoffs & $=1$ if the firm has established one or more spinoffs as a result of the SBIR \\
& program: 0 otherwise \\
newtechnology & $=1$ if the firm has previously received a Phase I award to research a technology \\
& is related to the project/technology supported by this Phase II award: 0 \\
otherwise & $=1$ if the Phase II project was funded by DOD: 0 otherwise \\
DOD & $=1$ if the Phase II project was funded by DOE: 0 otherwise \\
DOE & $=1$ if the Phase II project was funded by NASA: 0 otherwise \\
NASA & $=1$ if the Phase II project was funded by NIH: 0 otherwise \\
NIH &
\end{tabular}

Note: $N S F$ is subsumed in the intercept term. 
Table 3

Descriptive Statistics on the Variables $(n=1567)$

\begin{tabular}{lccc}
\hline Variable & Mean & Standard Deviation & Range \\
\hline emergent & 0.105 & 0.306 & $0 / 1$ \\
commercialization $_{\text {award }}^{*}$ & 0.867 & 0.339 & $0 / 1$ \\
employees & 650.697 & 254.922 & $14.83-4237$ \\
bussinessbackground & 30.562 & 56.187 & $1-451$ \\
spinoffs & 0.3447 & 0.427 & $0-1$ \\
newtechnology & 0.209 & 0.407 & $0 / 1$ \\
DOD & 0.468 & 0.499 & $0 / 1$ \\
DOE & 0.479 & 0.499 & $0 / 1$ \\
NASA & 0.087 & 0.283 & $0 / 1$ \\
NIH & 0.099 & 0.299 & $0 / 1$ \\
\hline
\end{tabular}

* As noted above, it is not uncommon for an agency to award add-on amounts of money to a Phase II project. This is often the case with DOD awards. 64 of the 1567 Phase II awards exceeded, in \$2005, \$1 million, and 77\% of those Phase II awards were funded by DOD. 
Table 4

Correlation Matrix of the Variables $(n=1567)$

\begin{tabular}{|c|c|c|c|c|c|c|c|c|}
\hline & 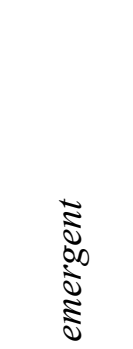 & 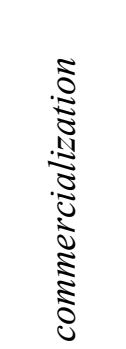 & $\begin{array}{l}\widetilde{J} \\
\vdots \\
\vdots \\
\vdots \\
\vdots\end{array}$ & 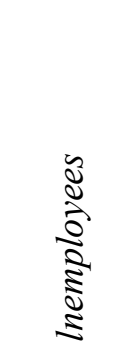 & 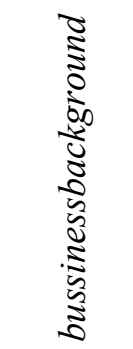 & 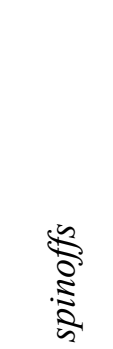 & 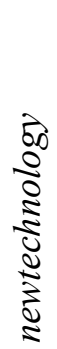 & $\stackrel{5}{>}$ \\
\hline emergent & 1 & & & & & & & \\
\hline commercialization & -0.032 & 1 & & & & & & 1.029 \\
\hline lnaward & 0.017 & 0.008 & 1 & & & & & 1.245 \\
\hline lnemployees & $-0.067 *$ & -0.027 & 0.042 & 1 & & & & 1.049 \\
\hline bussinessbackground & $0.084 *$ & 0.019 & -0.023 & $0.045^{*}$ & 1 & & & 1.018 \\
\hline spinoffs & $0.011 *$ & 0.002 & -0.016 & $0.110^{*}$ & $0.096^{*}$ & 1 & & 1.025 \\
\hline newtechnology & $-0.116^{*}$ & 0.039 & $-0.080 *$ & $0.123 *$ & -0.017 & -0.027 & 1 & 1.030 \\
\hline
\end{tabular}

* significant at the .05 -level or greater 
Table 5

Mean Value of Firm Projects with Sold Technology Rights, emergent, by Binary Variables

\begin{tabular}{lc}
\hline & emergent \\
\hline $\begin{array}{l}\text { commercialization }=0(\mathrm{n}=208) \\
\text { commercialization }=1(\mathrm{n}=1359)\end{array}$ & 0.130 \\
& 0.101 \\
spinoffs $=0(\mathrm{n}=1239)$ & 0.087 \\
spinoffs $=1(\mathrm{n}=328)$ & 0.171 \\
newtechnology=0 $(\mathrm{n}=833)$ & 0.138 \\
newtechnology=1 $(\mathrm{n}=734)$ & 0.067 \\
DOD $=1(\mathrm{n}=751)$ & 0.107 \\
DOE $=1(\mathrm{n}=137)$ & 0.088 \\
$N A S A=1(\mathrm{n}=155)$ & 0.058 \\
$N I H=1(\mathrm{n}=384)$ & 0.107 \\
$N S F=1(=140)$ & 0.157 \\
\hline
\end{tabular}


Table 6

Average Marginal Effects from the Probit Regressions, Dependent Variable is emergent

\begin{tabular}{lcc}
\hline Variable & $(1)$ & $(2)$ \\
\hline commercialization & $-0.031^{*}$ & $-0.034^{* *}$ \\
lnaward & $0.033^{*}$ & $0.068^{* * *}$ \\
lnemployees & $-0.016^{* * * *}$ & $-0.016^{* * * *}$ \\
bussinessbackground & $0.053^{* * * *}$ & $0.053^{* * * *}$ \\
spinoffs & $0.073^{* * * *}$ & $0.076^{* * * *}$ \\
newtechnology & $-0.061^{* * * *}$ & $-0.058^{* * * *}$ \\
DOD & $-0.056^{* * *}$ & $-0.072^{* * *}$ \\
DOE & $-0.071^{* *}$ & $-0.092^{* * *}$ \\
NASA & $-0.098^{* * * *}$ & $-0.113^{* * * *}$ \\
NIH & $-0.051^{* *}$ & $-0.064^{* * *}$ \\
& & \\
Likelihood ratio & 65.332 & 68.259 \\
$\mathrm{n}$ & 1567 & 1503 \\
\hline
\end{tabular}

Note: Projects funded by the NSF are subsumed in the intercept term.

$* * * *$ significant at 0.01 -level, ${ }^{* * *}$ significant at 0.05 -level, ${ }^{* *}$ significant at 0.10 -level, ${ }^{*}$ significant at 0.15 -level 


\section{References}

Allen, T.J., Lee, D.M., Tushman, M.L., 1980. R\&D performance as a function of internal communication, project management, and the nature of the work. IEEE Trans. Eng. Manag. $1,2-12$.

Altuntas, S., Dereli, T., Kusiak, A., 2015. Forecasting technology success based on patent data. Technol. Forecast. Soc. Change 96, 202-214.

Aristei, D., Vecchi, M., Venturini, F., 2016. University and inter-firm R\&D collaborations: Propensity and intensity of cooperation in Europe. J. Tech. Trans. 41(4), 841-871.

Asmawi, A., Mohan, A.V., 2011. Unveiling dimensions of organizational culture: An exploratory study in Malaysian R \& D organizations. R\&D Manag. 41(5), 509-523.

Audretsch, D.B., Obschonka, M., Gosling, S.D., Potter, J., 2017. A new perspective on entrepreneurial regions: linking cultural identity with latent and manifest entrepreneurship. Sm. Bus. Econ. 48(3), 681-697.

Becker, M.C., Zirpoli, F., 2017. How to avoid innovation competence loss in R\&D outsourcing. Calif. Manag. Rev. 59(2), 24-44.

Bönte, W., Piegeler, M., 2013. Gender gap in latent and nascent entrepreneurship: Driven by competitiveness. Sm. Bus. Econ. 41(4), 961-987.

Caiazza, R., Belitski, M., Audretsch, D.B., 2020. From latent to emergent entrepreneurship: The knowledge spillover construction circle. J. Tech. Trans. 45(3), 659-704.

Caiazza, R. Richardson, A., Audretsch, D.B., 2015. Knowledge effects on competitiveness: from firms to regional advantage. J. Tech. Trans. 40(6), 899-909.

Cantner, U., Cunningham, J.A., Lehmann, E.E., Menter, M., 2020. Entrepreneurial ecosystems: a dynamic lifecycle model. Sm. Bus. Econ. https://doi.org/10.1007/s11187-020-00316-0.

Carbonell, P., Escudero, A.I.R., Aleman, J.L.M., 2004. Technology newness and impact of go/no-go criteria on new product success. Market. Ltrs. 15(2-3), 81-97.

Corolleur, C.D., Carrere, M., Mangematin, V., 2004. Turning scientific and technological human capital into economic capital: The experience of biotech start-ups in France. Res. Policy 33(4), 631-642.

Davidsson, P., Wiklund, J., 2001. Levels of analysis in entrepreneurship research: Current research practice and suggestions for the future. Ent. Theory. Pract. 25(4), 81-100. 
Falk, M., 2012. Quantile estimates of the impact of R\&D intensity on firm performance. Sm. Bus. Econ. 39(1), 19-37.

Fatoki, O.O., Chindoga, L., 2012). Triggers and barriers to latent entrepreneurship in high schools in South Africa. J. Soc. Sci. 31(3), 307-318.

Fernández-Serrano, J., Romero, I., 2014. About the interactive influence of culture and regulatory barriers on entrepreneurial activity. Inter. Ent. Manag. J. 10(4), 781-802.

Fey, C.F., Birkinshaw, J., 2005. External sources of knowledge, governance mode, and R\&D performance. J. Manag. 31(4), 597-621.

Grilo, I., Thurik, A.R., 2006. Entrepreneurship in the old and new Europe. In: Santarelli, E. (Ed.), Entrepreneurship, Growth, and Innovation, Springer, Boston, pp. 75-103.

Grimpe, C., Kaiser, U., 2010. Balancing internal and external knowledge acquisition: The gains and pains from R\&D outsourcing. J. Manag. Stud. 47(8), 1483-1509.

Hagedoorn, J., Wang, N., 2012. Is there complementarity or substitutability between internal and external R\&D strategies? Res. Policy 41(6), 1072-1083.

Hart, S., Hultink, E.J., Tzokas, N., Commandeur, H.R., (2003). Industrial companies' evaluation criteria in new product development gates. J. Product Innov. Manag. 20(1), 22-36.

Hayter, C.S., Link, A.N., Scott, J.T., 2018. Public-sector entrepreneurship. Oxford Rev. Econ. Policy 34, 676-694.

Kleinknecht, A., Reijnen, J.O., 1992. Why do firms cooperate on R\&D? An empirical study. Res. Policy 21(4), 347-360.

Kotabe, M., Mol, M.J., Ketkar, S., 2008. An evolutionary stage model of outsourcing and competence destruction: A triad comparison of the consumer electronics industry. Manag. Inter. Rev. 48(1), 65-94.

Lerner, J., (1994). The importance of patent scope: an empirical analysis. RAND J. Econ. 25(2), $319-333$.

Leyden, D.P., Link, A.N., 2015. Public Sector Entrepreneurship: U.S. Technology and Innovation Policy, Oxford University Press, New York.

Lin, B.W., Lee, Y., Hung, S.C., 2006. R\&D intensity and commercialization orientation effects on financial performance. Journal of Business Research 59(6), 679-685.

Link, A.N., Scott, J.T., 2012. Employment Growth from Public Support of Innovation in Small Firms, W.E. Upjohn Institute for Employment Research, Kalamazoo. 
Lukas, B.A., Menon, A., Bell, S.J., 2002. Organizing for new product development speed and the implications for organizational stress. Indust. Market. Manag. 31(4), 349-355.

Martín-de Castro, G., Delgado-Verde, M., Navas-López, J E., Cruz-González, J., 2013. The moderating role of innovation culture in the relationship between knowledge assets and product innovation. Technol. Forecast. Soc. Change 80(2), 351-363.

Masuda, T., 2006. The determinants of latent entrepreneurship in Japan. Sm. Bus. Econ. 26(3), $227-240$.

National Research Council (NRC), 2008. An Assessment of the SBIR Program, The National Academies Press, Washington, DC.

Sosa, M.L., 2011. From old competence destruction to new competence access: Evidence from the comparison of two discontinuities in anticancer drug discovery. Organ. Sci. 22(6), 15001516.

Tsvetkova, A., Mark Partridge, M., 2019. Knowledge-based service economy and firm entry: An alternative to the knowledge spillover theory of entrepreneurship. Sm. Bus. Econ. https://doi:10.1007/s11187-019-00193-2.

Tsai, K.H., Wang, J.C., 2004. The R\&D performance in Taiwan's electronics industry: A longitudinal examination. R\&D Manag. 34(2), 179-189.

Veugelers, R., Cassiman, B., 2005. R\&D cooperation between firms and universities: Some empirical evidence from Belgian manufacturing. Inter, J. Ind. Organ. 23(5-6), 355-379.

Yeh, M.L., Chu, H.P., Sher, P.J., Chiu, Y.C., 2010. R\&D intensity, firm performance and the identification of the threshold: Fresh evidence from the panel threshold regression model. Applied Econ. 42(3), 389-401. 